\title{
Application of the Ultimate Hanging Arch Length of the Layered Roof with Anchors and the Gob-Side Entry Retaining
}

\author{
Peng Li $\mathbb{D}^{1,2}$ Xigui Zheng $\mathbb{D}^{1,2,3}$ Xiaowei Guo $\mathbb{C}^{1,},{ }^{1,2}$ Boyang $L i \mathbb{D}^{1,2}$ and Cong Wang $\mathbb{D}^{1,2}$ \\ ${ }^{1}$ Key Laboratory of Deep Coal Resource Mining, Ministry of Education, School of Mines, \\ China University of Mining and Technology, Xuzhou 221116, Jiangshu, China \\ ${ }^{2}$ School of Mines, China University of Mining and Technology, Xuzhou 221116, Jiangsu, China \\ ${ }^{3}$ School of Mining and Civil, Liupanshui Normal University, Liupanshui 553004, Guizhou, China \\ Correspondence should be addressed to Xiaowei Guo; kdguoxiaowei@163.com
}

Received 27 September 2021; Revised 16 October 2021; Accepted 19 October 2021; Published 1 November 2021

Academic Editor: Xiao Wang

Copyright ( 2021 Peng Li et al. This is an open access article distributed under the Creative Commons Attribution License, which permits unrestricted use, distribution, and reproduction in any medium, provided the original work is properly cited.

\begin{abstract}
The gob-side entry retaining plays an important role in improving working face ventilation, alleviating working face connection, and increasing mining revenue. According to the characteristics of the crossheading roof at the 2103 working face of a mine in Shanxi, a structural mechanics model of the roof was established to derive the theoretical formulae for the ultimate hanging arch length of the layered roof with anchors and the initial support resistance of the entry-side support. The influence factors of the ultimate hanging arch length were evaluated using local sensitivity analysis. Based on the theoretical study, the work proposed the collaborative support technology of the crossheading, collaborative support at the 2103 working face. The results showed that the ultimate hanging arch length was most influenced by the width of the plastic zone, followed by the width of the roadway, supporting strength, anchoring strength, layered thickness, and mining depth, while the ultimate tensile strength had little influence. The initial support resistance of the entry-side supports was closely related to the ultimate hanging arch length and the process of gob-side entry retaining. The improved entry-retaining supporting process could control the sharp surface convergence of the surrounding rocks of the entry retaining, the sinkage of the roof of the entry-retaining section was controlled below $100 \mathrm{~mm}$, and that of the advanced section was controlled below $50 \mathrm{~mm}$. The stability of the supports next to the entry is improved, and the needs of the site project are met.
\end{abstract}

\section{Introduction}

Gob-side entry retaining retains the haulage roadway of the upper-section working face for ventilation of the lowersection working face by strengthening the supports or using other effective methods after the upper section of the working face has been mined [1-4]. It has been highly valued by research departments and coal mining enterprises because of its advantages of easing mining succession tension, realizing coal pillar-free mining, improving coal resource recovery rate, isolating empty areas, avoiding air leakage, realizing Y-shaped ventilation, and solving corner gas accumulation. However, the gob-side entry retaining is subjected to the influence of two mining with strong mine pressure, and the rock destruction zone and plastic zone around the entry increases significantly, so maintenance is very difficult [5-8]. A large number of scholars have studied the interaction between the surrounding rock and supports, the law of surrounding rock activity along the gob-side entry retaining, and the supports in the entry, with useful results.

$\mathrm{Li}$ and Hua [9] studied the interaction between the key block and the surrounding rock along the gob-side entry retaining to determine the stability criterion of the key block, thus deriving the calculation formula of the support resistance next to the entry. Li [10] analyzed the process of rock movement and its deformation characteristics of the roof along the gob-side entry retaining. The design principles of controlling the support resistance of the filling body along the gob-side entry retaining at each stage are determined to establish the corresponding mathematical model of support 
resistance and reasonable compression. Xie [11] used numerical analysis software UDEC to establish the corresponding numerical analysis model and analyzed in detail the movement law of the surrounding rock along the integrated gob-side entry retaining. Han et al. [12] considered that the slow sinking of the hard roof plate with long-term overhang and the sudden fracture with violent incoming pressure are the root causes of disturbance along the gobside entry retaining. Changing the fracture location, timing, and structure through active fracturing can realize the active control of the "big structure" of the roof. The dual active control mechanism of "decompression-anchoring" is described using theoretical analysis, numerical simulation, and industrial tests to address the problem of maintenance and control in the hard roof. Zhang et al. [13] focused on the problem of direct top stability control of the loose and broken top plate along the gob-side entry retaining, such as the released top coal and composite top plate in comprehensive mining. According to the spatial and temporal characteristics of the top plate activity along the gob-side entry retaining, the elastic damage mechanics model of the direct top in the filling area is established, with the expression of the direct top stress distribution in the filling area derived. The evolution law of direct top stress distribution in the filling area is studied to obtain the equations of direct top tensile stress range and horizontal misalignment range in the filling area and the corresponding evolution law.

Zheng et al. [14] proposed the in situ coal pillar containment technology for the technical difficulties faced in the traditional gob-side entry retaining. The "limited deformation" in situ coal column mechanics model is established, and the principle of structural synergistic support is proposed to determine the synergistic rock control technology of anchor beam net rope as basic support and $\pi$-type steel beam + monolithic pillar as reinforced support. Kan et al. [15] clarified the movement law of the overlying rock layer of the secondary gob-side entry retaining for the problem of keeping it as a return wind passage for a long time after reusing it. A structural model of secondary gob-side entry retaining on the roof is established, with the concept of secondary along-air stay lane surrounding rock support structure proposed. Wu et al. [16], aiming at the control problem that the roof of the deep shaft along the gob-side entry retaining was difficult to form the bearing structure or even the topping disaster, integrated field research, theoretical analysis, and actual measurement methods and classified the deformation and damage forms in depth. A "multiprotection structure" control system, with the composition, control principle, support materials, and support timing studied.

However, the ultimate hanging arch length of the cantilever beam in the anchored state within the gob-side entry retaining after retrieval is usually neglected. Therefore, based on the research results of previous scholars, the work further studied the problem of gob-side entry retaining. By establishing the mechanical calculation model of the layered top slab in the anchored state, the mechanical expression of the ultimate hanging arch length of the top slab was derived and its influencing factors were evaluated primarily and secondarily. Based on the solved value of overhanging roof distance, the interaction model between entry-retaining support and the direct roof was analyzed to derive the mathematical expression for calculating the initial support resistance of entry-retaining fillers. The research results are of great practical guidance for the control of the top slab of the gob-side entry retaining and the understanding of the interaction mechanism of the surrounding rock and support. It has been applied to the field-engineering practice.

\section{Mechanics Modeling and Calculation under Anchoring Condition}

2.1. Mechanical Model of the Layered Roof with Anchors in the Entry Retaining. Both theory and practice show that due to the low tensile strength of the rock seam, most of the roof damage is in the form of compound flexural breakage under the action of self-weight and axial thrust. The breakage rule of the roof is generally to break after leaving the seam first (see Figure 1), and a fracture is produced in the overhanging coal wall. Then, the overhanging roof will be kept in equilibrium with the clamping structure. When the axial thrust reaches a certain limit, the bending deformation generated by it will be a vicious circle. The beam cannot maintain the new equilibrium state, leading to damage [17-19].

Basic assumptions are as follows. (1) The surrounding rock satisfies all the assumptions of classical linear elasticity theory, that is, continuous, completely linear elastic, uniform, isotropic, small deformation, and mainly studies the plane deformation state. (2) The roof is in small deformation before breaking, and its overburden load does not change significantly with the advance of working face, and it is a uniform load. (3) The coal seam is strong and large, and the plastic deformation of the coal wall caused by retraction does not change its supporting effect on the roof plate. (4) The anchoring force of the anchor section is equal, and the support force provided by the anchor solid is evenly distributed on the rock layer of the roof. (5) Rock beam (plate) meets the basic conditions of elastic foundation beam (plate).

\subsection{Calculation of the Ultimate Hanging Arch Length of the} Layered Roof with Anchors. Based on the analysis of the lithology of the roof, the breaking process, and the characteristics of incoming pressure, we divided the roof motion into two processes: significant motion and relatively stable motion. The corresponding mechanical models were the rock beam model with solid support at both ends and the cantilever beam model with solid support at one end and cantilever at the other, and the work focused on its relative stability. Considering the unfilled wall section behind the lagging working face, it was approximated as a short-time cantilever beam model [20-23]. The width of the stress limit equilibrium zone was taken as the elastic zone boundary, and the mechanical calculation equations were established to give the mathematical expressions of its limit equilibrium. 


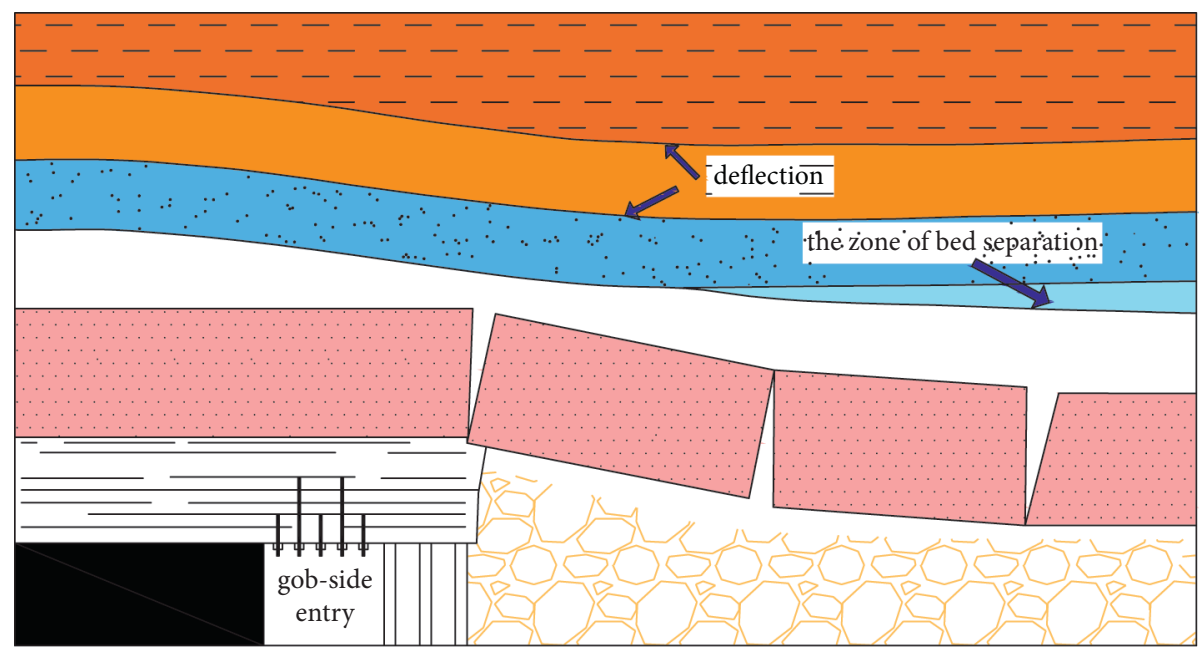

FIGURE 1: Flexure and breakage of the roof.

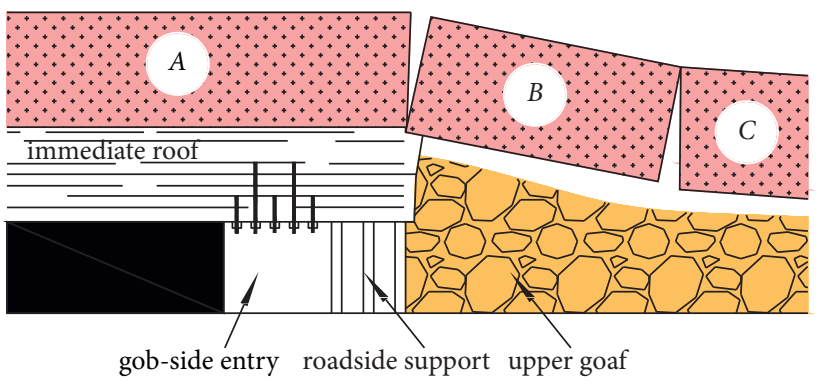

(a)



(b)

Figure 2: Model and mechanical calculation of the rock-beam breaking structure. (a) Model of top-plate breaking structure. (b) Analysis of cantilever beam force.

In the following, the formula for the ultimate hanging arch length is analyzed.

In Figure 2(b), the horizontal direction load is neglected under the action of overlying uniform load $q$, pillar initial support force $P$, coal pillar support force $F_{m}$ in the plastic zone, and anchorage uniform load $q_{0}$. From mechanical equilibrium equation $\sum F_{y}=0, \sum M_{A}=0$, we obtain $q l-$ $F_{m}-q_{0} l_{0}-P-F_{A}=0$ and $M_{A}+F_{m} \times\left(x_{0} / 2\right)$ $+q_{0} l_{0}\left(\left(l_{0} / 2\right)+x_{0}\right)+P\left(l_{0}+x_{0}\right)-\left(q l^{2} / 2\right)=0 . \quad M_{A}$ is the bending moment at the fixed end, $F_{A}$ is the y-directional binding force at the fixed end, $x_{0}$ is the width of the stress limit balance zone, $F_{m}$ acts at $x_{0} / 2$. The width of stress's ultimate equilibrium zone $x_{0}$ can be obtained from [22]. $\gamma$ is the rock capacity; $H$ is the mining depth; $m$ is the thickness of coal seam mining; $k$ is the stress concentration coefficient; $A$ is the lateral pressure coefficient; $P_{x}$ is the support resistance of the bracket to the coal gang; $C_{0}$ and $\varphi$ are the cohesive force and internal friction angle at the intersection of the coal seam and the roof, respectively:

$$
x_{0}=\frac{m \cdot A}{2 \operatorname{tg} \varphi_{0}} \ln \left(\frac{k \gamma H+\left(C_{0} / \operatorname{tg} \varphi_{0}\right)}{\left(C_{0} / \operatorname{tg} \varphi_{0}\right)+\left(P_{x} / A\right)}\right) .
$$

As measured, the length of $x_{0}$ is generally $2-10 \mathrm{~m}$.

There are three unknown quantities, and only two can be listed. This solution belongs to the primary super-stationary problem, for which another equilibrium equation needs to be sought.

Assuming that the rock beam is a rigid-like body, deflections $w_{1}$ and $w_{2}$ at the point of action of $F_{m}$ and $P$ approximately satisfy the compatibility equation of deformation (see Figure 3):

$$
\frac{w_{1}}{w_{2}}=\frac{x_{0}}{2\left(l_{0}+x_{0}\right)} \text {. }
$$

By the superposition method, $w_{1}=w_{q 1}+w_{F m 1}+w_{q 01}+$ $w_{P 1}$ and $w_{2}=w_{q 2}+w_{F m 2}+w_{q 02}+w_{P 2} ; \quad w_{q 1}, w_{q 2}, w_{F m 1}$, $w_{F m 2}, w_{q 01}, w_{q 02}, w_{P 1}$, and $w_{P 2}$ are the deflection values caused at action points $\mathrm{Fm}$ and $P$ by $q, q_{0}, F_{m}$, and $P$, respectively.

After substituting the result of the calculation into (2), $\left(w_{1} / w_{2}\right)=\left(w_{q 1}+w_{q 01}+w_{P 1}+\left(F_{m} x_{0}^{3} / 24 E I\right) / w_{q 2}+w_{q 02}\right.$ $\left.+w_{P 2}+\left(F_{m} x_{0}^{2} / 24 E I\right)\left(3 l_{0}+(5 / 2) x_{0}\right)\right)=\left(x_{0} / 2\left(l_{0}+x_{0}\right)\right)$. The solution is $F_{m}=\left(48 E I\left[2 A\left(l_{0}+x_{0}\right)-B x_{0}\right] / 2 l_{0} x_{0}^{3}+x_{0}^{4}\right)$, where $\quad A=w_{q 1}+w_{q 01}+w_{P 1} ; \quad B=w_{q 2}+w_{q 02}+w_{P 2}$. 


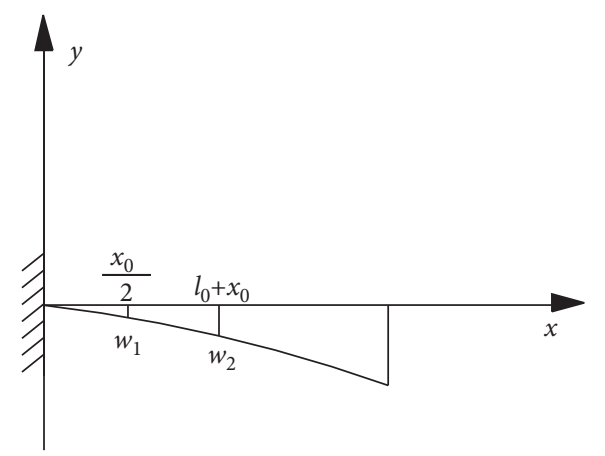

Figure 3: Flexural deflection of the cantilever beam.

Applying the knowledge of material mechanics, the bending moment equation of the beam is

$$
M(x)=\left\{\begin{array}{l}
\frac{-q x^{2}}{2}+F_{A} x-M_{A},\left[0, \frac{x_{0}}{2}\right] \\
-\frac{q x^{2}}{2}+\left(F_{A}+F_{m}\right) x-\frac{F_{m} x_{0}}{2}-M_{A},\left[\frac{x_{0}}{2}, x_{0}\right] \\
-\frac{q x^{2}}{2}+\frac{q_{0}\left(x-x_{0}\right)^{2}}{2}+\left(F_{A}+F_{m}\right) x-\frac{F_{m} x_{0}}{2}-M_{A},\left[x_{0}, x_{0}+l_{0}\right] ; \\
-\frac{q x^{2}}{2}+\left(F_{A}+F_{m}+q_{0} l_{0}+P\right) x-\frac{F_{m} x_{0}}{2}-q_{0} l_{0}\left(x_{0}+\frac{l_{0}}{2}\right)-P\left(x_{0}+l_{0}\right)-M_{A},\left[x_{0}+l_{0}, l\right] .
\end{array}\right.
$$

In $\quad F_{A}=q l-q_{0} l_{0}-F_{m}-P, \quad M_{A}=\left(q l^{2} / 2\right) \quad-q_{0} l_{0}$ $\left(x_{0}+\left(l_{0} / 2\right)\right)-P\left(l_{0}+x_{0}\right)-\left(F_{m} x_{0} / 2\right)$ are obtained by solv$\operatorname{ing} \sum M_{A}=0, \sum F_{y}=0$ jointly.

In $\left[0,\left(x_{0} / 2\right)\right]$, let $(\mathrm{d} M(x) / \mathrm{d} x)=0$, the bending moment at $x=\left(F_{A} / q\right)$ takes maximum value $M_{1}=\left(F_{A}^{2} / 2 q\right)-M_{A}$; in $\left[\left(x_{0} / 2\right), x_{0}\right]$, the bending moment at $x=\left(F_{A}+F_{m} / q\right)$ takes maximum value $M_{2}=\left(\left(F_{A}+F_{m}\right)^{2} / 2 q\right)-\left(F_{m} x_{0} / 2\right)-M_{A}$; in $\left[x_{0}, x_{0}+l_{0}\right]$, the bending moment at $x=\left(F_{A}+F_{m}-q_{0} x_{0} / q-q_{0}\right)$ takes maximum value $M_{3}=$

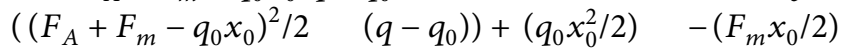
$-M_{A}$; in $\left[x_{0}+l_{0}, l\right]$, the bending moment at $x=\left(F_{A}+F_{m}-\right.$ $\left.q_{0} l_{0}+P / q\right)$ takes maximum value $M_{4}=\left(q l^{2} / 2\right)$ $-q_{0} l_{0}\left(x_{0}+\left(l_{0} / 2\right)\right)-P\left(x_{0}+l_{0}\right)-\left(F_{m} x_{0} / 2\right)-M_{A}$. The bending moment values at each turning point can be found from Table 1.

Accordingly, we make the cantilever beam moment diagram roughly as follows.

By combining Figure 4 and comparing the extreme bending moments and values at each turning point, we can obtain the maximum value of bending moment (taking the absolute value) at the fixed end: $M_{\max }=$ $\max \left\{\left|M_{1}\right|,\left|M_{2}\right|,\left|M_{3}\right|,\left|M_{4}\right|,\left|M_{5}\right|,\left|M_{6}\right|,\left|M_{7}\right|,\left|M_{8}\right|,\left|M_{9}\right|\right\}=$ $\left|M_{5}\right|$. Considering the low tensile strength of the rock cantilever beam, the tensile stress generally exceeds the limit and causes the rock beam to be destabilized and broken. The strength condition was calculated by (4), and (5) can be obtained:

$$
\begin{array}{r}
\sigma_{\max }=\frac{M_{\max }}{W}=\frac{M_{5}}{W}=\left[\sigma_{t}\right], \\
\frac{\left|A_{0} q l^{2}-B_{0} q l+C_{0} q_{0}+D_{0} q+E_{0} P\right|}{W}=\left[\sigma_{t}\right] .
\end{array}
$$

In (5), $A_{0}=\left(-12\left(l_{0}+x_{0}\right)^{2}+7 x_{0}^{2}+8 l_{0} x_{0} / 2\left(2 l_{0} x_{0}+x_{0}^{2}\right)\right)$, $B_{0}=\left(\left(l_{0}+x_{0}\right)\left[x_{0}^{2}-4\left(l_{0}+x_{0}\right)^{2}\right] / 2 l_{0} x_{0}+x_{0}^{2}\right), \quad C_{0}=\left(6 l_{0}^{4}+\right.$ $\left.16 l_{0}^{3} x_{0}+15 l_{0}^{2} x_{0}^{2}+4 l_{0} x_{0}^{3} / 2\left(2 l_{0} x_{0}+x_{0}^{2}\right)\right), D_{0}=\left(\left(l_{0}+x_{0}\right)\left[\left(x_{0}^{3}\right.\right.\right.$ /8) $\left.\left.-\left(l_{0}+x_{0}\right)^{3}\right] / 2 l_{0} x_{0}+x_{0}^{2}\right)$, and $E_{0}=\left(\left(l_{0}+x_{0}\right)\left(8 l_{0}^{2}+2 x_{0}^{2}\right.\right.$ $\left.\left.+8 l_{0} x_{0}\right) / 2 l_{0} x_{0}+x_{0}^{2}\right)$, where $A_{0}=\left(-12\left(l_{0}+x_{0}\right)^{2}+7 x_{0}^{2}+8 l_{0}\right.$ $\left.x_{0} / 2\left(2 l_{0} x_{0}+x_{0}^{2}\right)\right), \quad B_{0}=\left(\left(l_{0}+x_{0}\right)\left[x_{0}^{2}-4\left(l_{0}+x_{0}\right)^{2}\right] / 2 l_{0} x_{0}\right.$ $\left.+x_{0}^{2}\right), \quad C_{0}=\left(6 l_{0}^{4}+16 l_{0}^{3} x_{0}+15 l_{0}^{2} x_{0}^{2}+4 l_{0} x_{0}^{3} / 2\left(2 l_{0} x_{0}+x_{0}^{2}\right)\right)$, $D_{0}=\left(\left(l_{0}+x_{0}\right)\left[\left(x_{0}^{3} / 8\right)-\left(l_{0}+x_{0}\right)^{3}\right] / 2 l_{0} x_{0}+x_{0}^{2}\right)$, and $E_{0}=$ $\left(\left(l_{0}+x_{0}\right)\left(8 l_{0}^{2}+2 x_{0}^{2}+8 l_{0} x_{0}\right) / 2 l_{0} x_{0}+x_{0}^{2}\right)$. Considering the layered roof as a combined beam with unit width, $n$ as the number of anchorage layers, and the thickness of each stratum as the combined beam of $h$, antibending section factor $W$ is $(1 / 6)(n h)^{2}$. After substituting into (5), (6) can be obtained: 
TABLE 1: Bending moment values at each turning point.

\begin{tabular}{lcc}
\hline Position & Bending moment value & Bending moment value after simplification \\
\hline$x=0$ & $M_{5}=-M_{A}$ & $\left(q l^{2}-F_{m} x_{0} / 2\right)-q_{0} l_{0}\left(x_{0}+\left(l_{0} / 2\right)\right)-P\left(l_{0}+x_{0}\right)$ \\
$x=\left(x_{0} / 2\right)$ & $M_{6}=-\left(q x_{0}^{2} / 8\right)+\left(F_{A} x_{0} / 2\right)-M_{A}$ & $-\left(q x_{0}^{2} / 8\right)+\left(\left(q l+q_{0} l_{0}+P\right) x_{0} / 2\right)-\left(q l^{2} / 2\right)+\left(q_{0} l_{0}^{2} / 2\right)-+P l_{0}$ \\
$x=x_{0}$ & $M_{7}=-\left(q x_{0}^{2} / 2\right)+\left(F_{A}+F_{m}\right) x_{0}-\left(F_{m} x_{0} / 2\right)-M_{A}$ & $-\left(q x_{0}^{2} / 2\right)+q l x_{0}+\left(q_{0} l_{0}^{2} / 2\right)-\left(q l^{2} / 2\right)+P l_{0}$ \\
$x=x_{0}+l_{0}$ & $M_{8}=\left(q_{0} l_{0}^{2}-F_{m} x_{0}-q\left(x_{0}+l_{0}\right) / 2\right)+\left(F_{A}+F_{m}\right)\left(x_{0}+l_{0}\right)-M_{A}$ & $-\left(q x_{0}^{2}+q l_{0}^{2}+q l^{2} / 2\right)-q x_{0} l_{0}+q l\left(x_{0}+l_{0}\right)$ \\
$x=l$ & $M_{9}=\left(q l^{2} / 2\right)-q_{0} l_{0}\left(x_{0}+\left(l_{0} / 2\right)\right)-P\left(x_{0}+l_{0}\right)-\left(F_{m} x_{0} / 2\right)-M_{A}$ & 0 \\
\hline
\end{tabular}

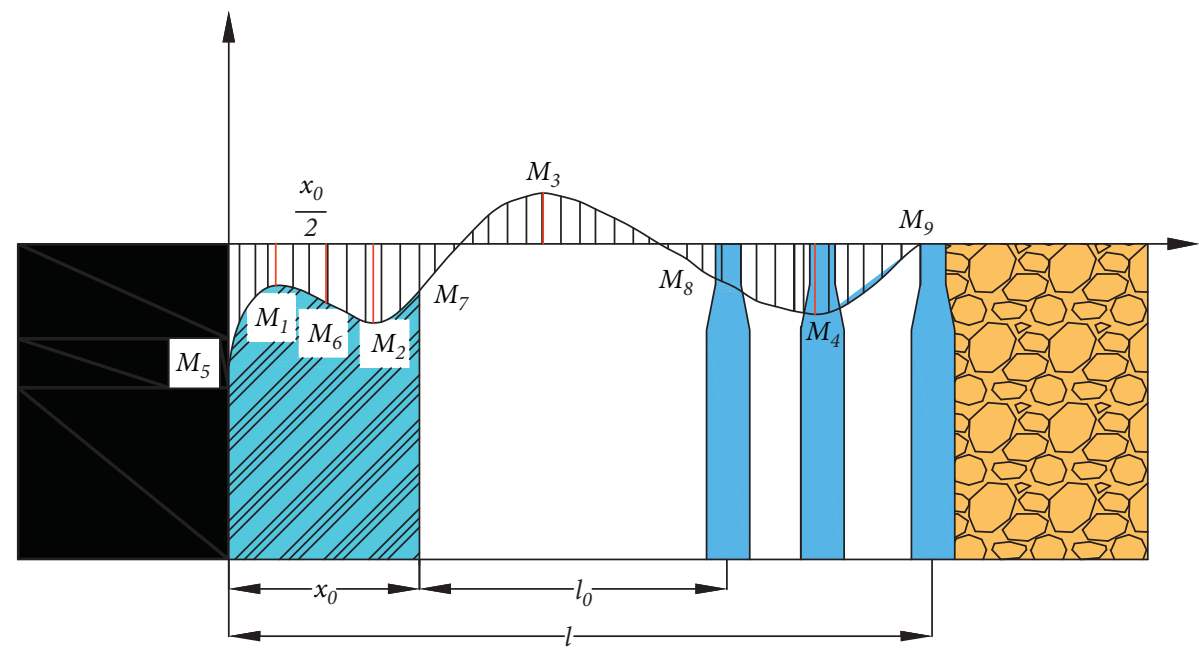

Figure 4: Cantilever-beam bending moment.

$$
l^{2}-\frac{B_{0}}{A_{0}} l+\frac{C_{0} q_{0}}{A_{0} q}+\frac{D_{0}}{A_{0}}+\frac{E_{0} P}{A_{0} q}-\frac{n^{2} h^{2}\left[\sigma_{t}\right]}{6 A_{0} q}=0
$$

and $K_{1}=\left(q_{0} / q\right)$ is defined as the anchorage strength factor, and $K_{2}=P / q$ is the support strength factor. The resulting solution is as follows:

$$
l=\frac{\left(B_{0} / A_{0}\right)+\sqrt{\left(B_{0}^{2} / A_{0}^{2}\right)-4\left(\left(C_{0} / A_{0}\right) K_{1}+\left(D_{0} / A_{0}\right)+\left(E_{0} / A_{0}\right) K_{2}+\left(n^{2} h^{2}\left[\sigma_{t}\right] / 6 A_{0} q\right)\right)}}{2} .
$$

\section{Parameter-Sensitivity Analysis of the Ultimate Hanging Arch Length of the Layered Top Plate with Anchors}

3.1. Parameter Sensitivity Analysis. Parameter changes lead to numerical changes in model behaviors, and sensitivity analysis is a measure of the extent to which a particular parameter change affects the model output results. It can qualitatively or quantitatively analyze the characteristics of the parameters affecting the ultimate hanging arch length, the effect of a single parameter, or different combinations of parameters on the model performance [24]. The work used the local sensitivity analysis to analyze the response variation of the cantilever-beam mechanics' model.

Local sensitivity analysis considers the effect of a change in a single parameter on the model response. The basic principle is to fix the other parameters and analyze only the model response results caused by the variation of a parameter in a small range $[25,26]$. Assuming our objective function is $f\left(x_{1}, x_{2}, \ldots, x_{i}, \ldots, x_{n}\right)$ with $n$ parameters, $x_{i}$ is the $i^{\text {th }}$ parameter among them, and $f\left(x_{i}\right)$ is the value of the sensitivity analysis of parameter $f\left(x_{i}\right)$ as a function value of a fixed design point. In addition to parameters $x_{i}, x_{1}, x_{2}, \ldots, x_{n}$ at this analysis point are fixed values. A small change in $x_{i}$ at this analysis point changes function $f(x)$ :

$$
s(i)=\frac{f\left(x_{1}, \ldots, x_{i}+\delta, \ldots, x_{n}\right)-f\left(x_{1}, \ldots, x_{i}, \ldots, x_{n}\right)}{\delta} .
$$

Equation (8) is the sensitivity value of function $f(x)$ to the variable parameter $x_{i}$. The larger the $S(i)$ value, the 
greater the influence of parameter $x_{i}$ on the function $f(x)$ [27]. Ultimate hanging arch length $l\left(x_{1}, x_{2}, \ldots, x_{i}, \ldots, x_{n}\right)$ has $n$ influencing factors. When $\delta$ tends to be infinitesimal, the calculated expression for the variation of sensitivity is obtained as follows:

$$
s(i)=\frac{\partial l\left(x_{i}\right)}{\partial x_{i}} \cdot \frac{x_{i}}{l\left(x_{i}\right)}=\frac{1}{l\left(x_{i}\right)}\left|\frac{\Delta l}{\beta_{i}}\right|,
$$

where $l\left(x_{i}\right)$ is the value of the hanging arch length at the fixed point, $\beta i$ the variation factor of parameter $x_{i}$, and $\Delta l$ is the variation value of the hanging arch length.

3.2. Evaluation of Local Sensitivity Analysis Results. Equation (7) was used to obtain the influencing parameter $\left(x_{0}, l_{0}, H, q_{0}, n, h,\left[\sigma_{t}\right]\right)$ of ultimate hanging arch length $l$. The sensitivity of a given factor was analyzed using the factor change method; that is, a single factor was taken as the variable and the rest of the factors were taken as the central values. Assuming $\pm 5 \%, \pm 10 \%, \pm 15 \%, \pm 20 \%$, and $\pm 25 \%$ fluctuations of each regulating factor, the valueadded $\Delta l$ of the hanging arch length was obtained, and the sensitivity of each parameter change was obtained by substituting into (9).

Figure 5 shows that hanging arch length $\Delta l$ increases by $\pm 1.41 \mathrm{~m}$ when the width of the plastic zone fluctuates by $\pm 25 \%$, and it is the most influential factor on $\Delta l$ among the parameters. The increased plastic zone makes the model boundary penetrate deeper into the coal mass. The coal wall provides more support to the overlying cantilever rock beam, resulting in the rock beam can have a larger overhead distance. When the width of the roadway fluctuates by $\pm 25 \%$, hanging arch length $\Delta l$ increases by $\pm 0.87 \mathrm{~m}$, which is the second most influential factor after the width of the plastic zone. As the width of the roadway increases, the range of the corresponding anchorage zone increases. For the layered roof slab, the effect of adding anchors [28] gives full play to the self-stabilizing ability of the rock mass and reduces the span of the roof. The ability of the roof to withstand deflection is further enhanced, and the ultimate suspension capacity is further increased. Analyzing the influence of anchorage strength and entryside support strength, when the parameters fluctuate $\pm 25 \%, \Delta l$ increases by \pm 0.27 and $\pm 0.60 \mathrm{~m}$, respectively. The support strength is more capable of increasing the hanging arch length than the anchorage strength. When the parameters fluctuate within the same range, increased $\Delta l$ caused by mining depth, stratification thickness, and ultimate tensile strength are all below $\pm 0.02 \mathrm{~m}$, which means that the hanging arch length is less affected by these three factors.

Figure 6 reflects the degree of influence of each factor, and the sensitivity of each parameter is ranked as $S\left(x_{0}\right)$ $>S\left(l_{0}\right)>S(P)>S\left(q_{0}\right)<S(h)>S(H)>S\left(\sigma_{t}\right)$. From this, the plastic zone width has the greatest influence on the hanging arch length, followed by the width of the roadway, support strength, anchorage strength, stratification thickness, mining depth, and ultimate tensile strength successively.

\section{Determination of the Support Resistance of the Entry-Retaining Support}

4.1. Immediate-Roof Mechanical Model. During the gob-side entry retaining, the upper roof is in stable condition. After the working face advances a certain distance, timely strengthening of the support plays an important role in controlling the deformation of the entry retaining. The support near the entry acts on the immediate roof to stop the delamination of the immediate roof and the upper roof above the bearing structure. The support near the entry retaining should provide a certain initial support force or inhibit the resistance of rock beam sinking to maintain the structural stability of the entry roof and fillers. Meanwhile, the initial resistance of the entry should cut off the immediate roof on the side of the mining area and guide the broken collapse of the upper roof to maintain the stability of the coal gang on the nonrecovery side and the entry-side support as the bearing support of the immediate roof. Figure 7 shows the established mechanical model of the support near the entry retaining and the immediate-roof mechanical model.

4.2. Calculation of the Support Resistance of the Entry-Side Support. After the immediate roof is stabilized, rock mass $A$, $B, C$, and $D$ in Figure 7 are temporarily stabilized under the support of the coal wall and the entry-side support. $\sum F_{y}=0$ is used to obtain the calculation formula of the initial support resistance:

$$
\begin{aligned}
& (q+\gamma h)\left(l-x_{0}\right)(j+u)-q_{1}\left(l_{0}+d\right)(j+u)-P_{u} \cdot u=0 \\
& P_{u}=\frac{(q+\gamma h)\left(l-x_{0}\right)(j+u)-q_{1}\left(l_{0}+d\right)(j+u)}{u}
\end{aligned}
$$

where $P_{u}$ is the support resistance of fillers, $l$ is the ultimate hanging arch length, calculated by (7), $q$ is the average load acting on the immediate roof, $\gamma$ is the unit weight of the immediate roof, $d$ is the width of the support zone near the entry, $j$ is the distance of the support near the entry from the heading stope, $u$ is the length of the entry-retaining every day, and $q_{1}$ is the average support strength of the entry support to the immediate roof.

\subsection{Analysis of Examples}

4.3.1. Project Overview. Coal 2\# was mainly mined in a mine in Shanxi with an average coal seam thickness of $1.62 \mathrm{~m}$. The retrieval height along the roof of coal $2 \#$ was $1.8 \mathrm{~m}$, with an average mining depth of $230 \mathrm{~m}$. The track crossheading was dug along the roof of the coal seam, and the immediate roof of the coal seam was mudstone with a thickness of $1.6 \mathrm{~m}$. The upper roof was fine sandstone with a thickness of $2.25 \mathrm{~m}$. The width and height of the entry section were $4.1 \times 2.2 \mathrm{~m}$. The lithology and physical and mechanical parameters of the roof of the entry can be found from Table 2, and the geological comprehensive histogram of 2 \# coal seam is shown in Figure 8 . 


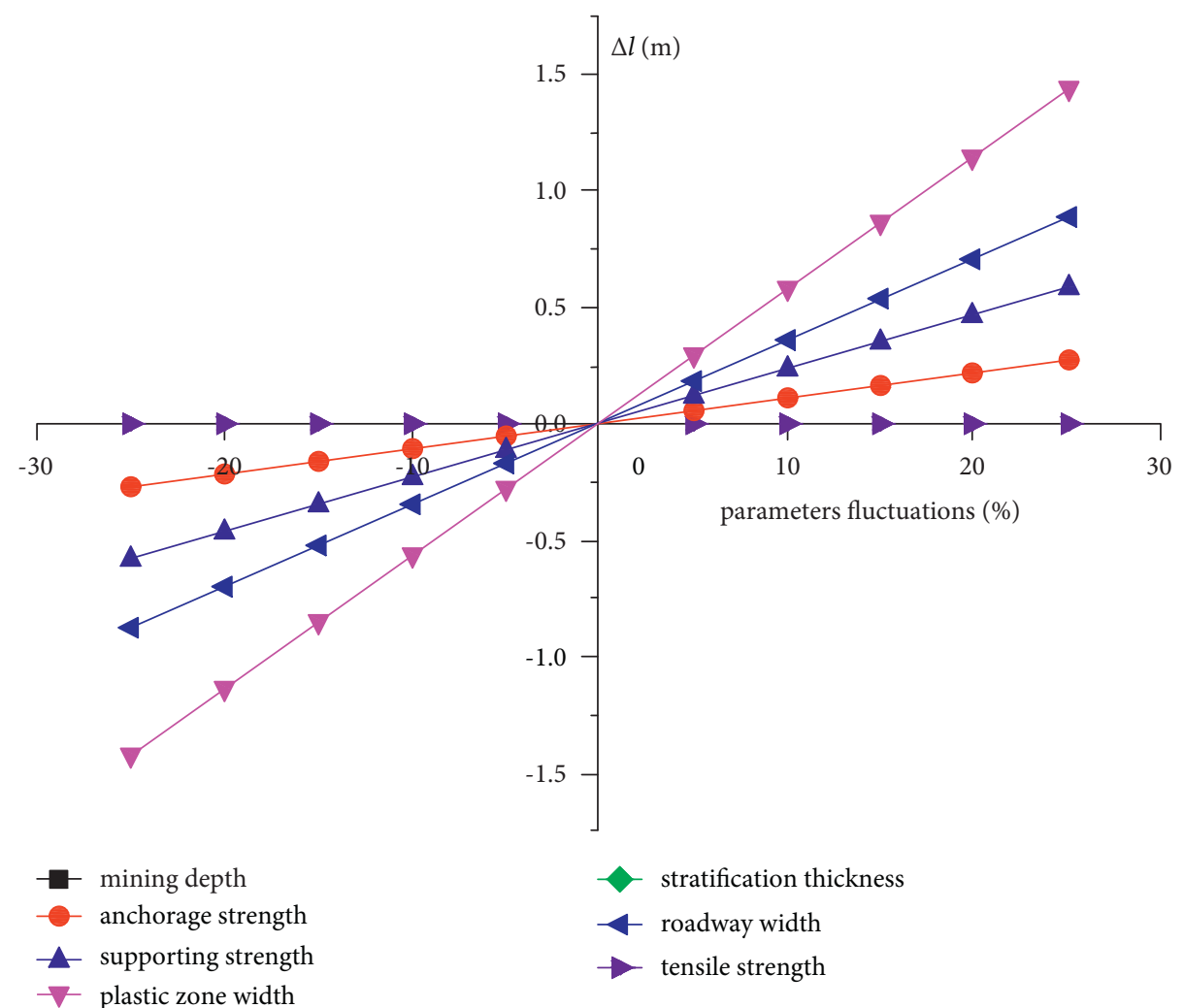

Figure 5: Relationship between the rate of change of each parameter and $\Delta l$.

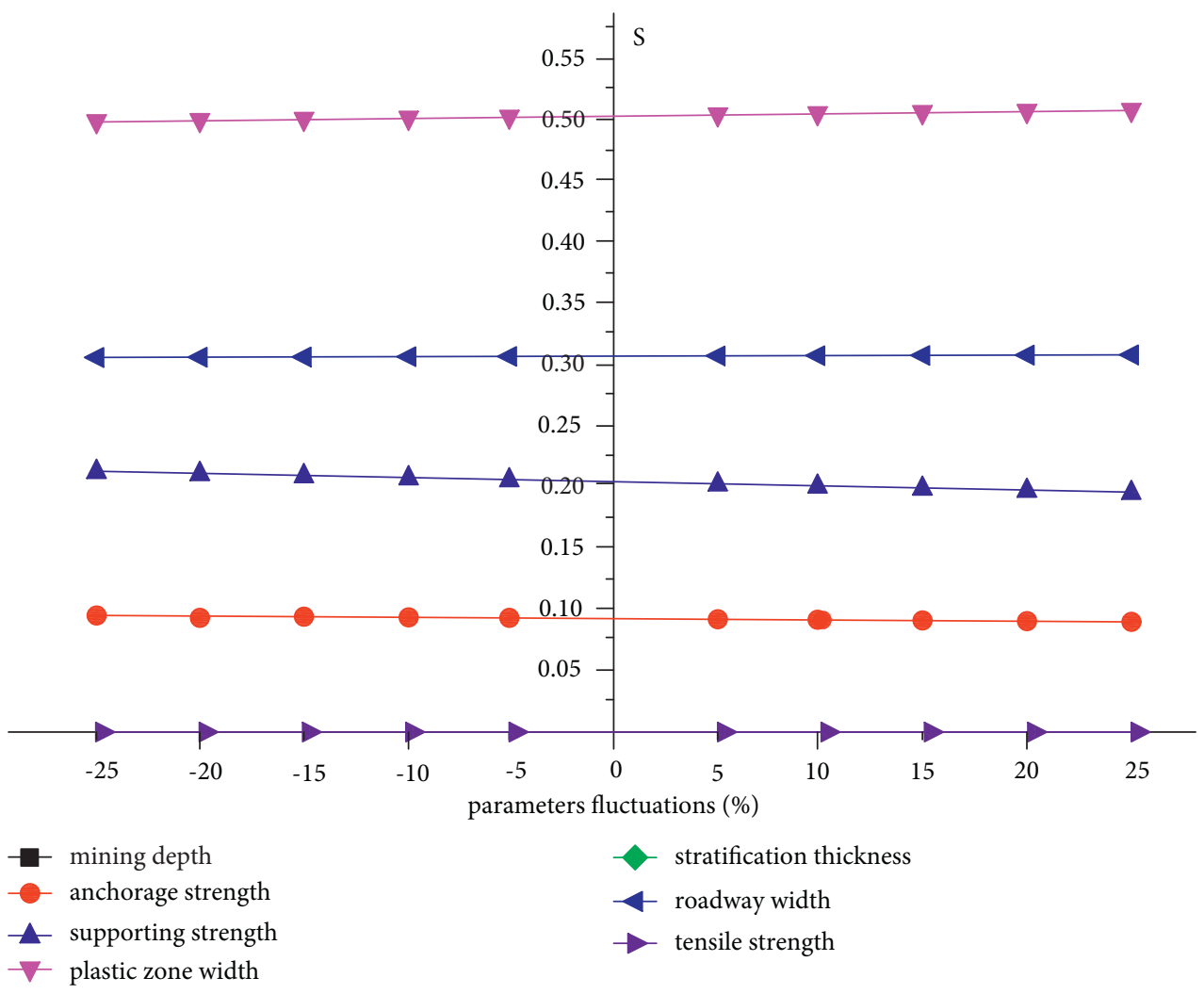

FigURE 6: Relationship between the rate of change of each parameter and S. 

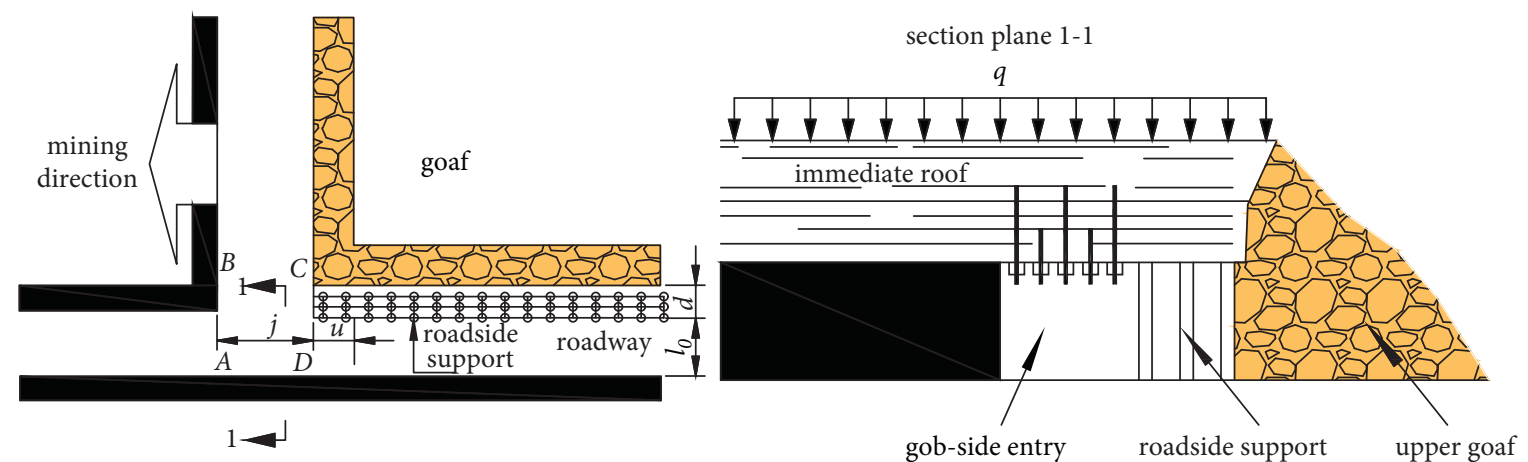

FIGURE 7: Mutual mechanical model of the support near the entry retaining and immediate roof.

4.3.2. Calculation of the Hanging Arch Length. The formula for calculating the load on the upper floor is used to obtain $q_{1}=57.6 \mathrm{KPa}, \quad\left(q_{2}\right)_{1}=72.2 \mathrm{KPa}, \quad\left(q_{3}\right)_{1}=83.3 \mathrm{KPa}, \quad$ and $\left(q_{4}\right)_{1}=31.0 \mathrm{KPa}$. The influences of the first, second, and third layers on the first layer should be considered, so the size of the load on the first layer of the upper floor is $83.3 \mathrm{KPa}$. Then, the load on the cantilever beam is $q=83.3+\gamma 1 h 1=124.9$ $(\mathrm{KPa})$, anchor preload is $80 \mathrm{kN}$, and $x_{0}$ is calculated as $2.98 \mathrm{~m}$ by (1); values of each parameter can be found from Table 3.

The data in Table 4 is substituted into (7) to find that the ultimate hanging arch length $l$ is $(10.2-10.5) \mathrm{m}$, which is consistent with the actual observation in the field.

4.3.3. Calculation of Initial Support Resistance of the Gob-Side Entry Retaining. The lower crossheading of the 2103 working face is the gob-side entry retaining, and the reinforced support section of the entry lags behind the working face by $4 \mathrm{~m}$. The parameters are as follows: $l=(10.2-10.5) \mathrm{m}$; $q=124.9 \mathrm{KPa} ; \quad \gamma=25 \mathrm{kN} / \mathrm{m}^{3} ; \quad d=2.2 \mathrm{~m} ; j=4 \mathrm{~m} ; u=6 \mathrm{~m}$; $q_{1}=125 \mathrm{KPa}$.

Each parameter is substituted into (11) to get initial support resistance $P_{u}=(166.7-229.2) \mathrm{kN} / \mathrm{m}$. Considering the safety factor taken as 1.2 , the initial uniaxial compressive strength of the entry-side support should be not less than $0.46 \mathrm{MPa}$.

\section{Cosupporting Technology}

5.1. Roof Support. The support strength of the roof needs to be increased to stabilize the roof anchorage structure before mining and in the entry-retaining period. Reference [29] was studied for comprehensive support design, and the basic parameters of reinforcement are as follows:

(1) A set of monolithic anchor ropes was supplemented in the middle of the roof, with anchor rope specification $\Phi 17.8 \times 5,200 \mathrm{~mm}$ and a rectangular tray of $300 \times 300 \times 15 \mathrm{~mm}$. Each anchor cable adopted 1 CK2335 and 2 Z2350 anchoring agents with preload not less than $80-100 \mathrm{kN}$. The row distance is $1,000 \mathrm{~mm}$, the same as anchor rods.

(2) Both sides of the roof were $400-600 \mathrm{~mm}$ from the gang, and the outward angle of the anchor cable was
20-30 . Equip with channel steel 14 and arrange in the form of the anchor cable beam with a beam length of $2.8 \mathrm{~m}$ and a hole distance of $2.4 \mathrm{~m}$. Each set of anchor cables was equipped with a $150 \times 100 \times 5 \mathrm{~mm}$ flat steel plate, and the anchor cable specification and anchoring performance and construction requirements were the same as those of the anchor cable in the middle of the floor.

(3) The order of reinforcement was carried out from inside out to the stopping line at the location of the working face.

5.2. Auxiliary Strengthening Support in the Entry Retaining. The internal auxiliary reinforcement range of the entry was $60 \mathrm{~m}$ ahead of the working face and the space left in the entry retaining. Four monohydraulic pillars with cross-articulated roof beams were used to strengthen the support in the advanced area. Five monoblock pillars were arranged in the gob-side entry retaining, and the bottom beam was installed to control the floor heave of the entry actively in the recovery period (see Figure 9).

The roof should be reinforced by slurry spraying when the following three conditions occur. (1) For the collapse column and continuous fault-zone-affected area, the roof sinks $500 \mathrm{~mm}$ or more or continuous netting. (2) For the small fault affected area, the interior of the entry retaining shows steps, with anchor cables pulled off. (3) Drenching sections is the third condition.

\subsection{In Situ Observation}

5.3.1. Observation Program. The deformation of the roadway surface is an important index reflecting the magnitude of the roadway surface displacement and the degree of convergence of the roadway section. The main indices include roof subsidence, floor swelling, and roadway displacement. The observed values can be used to judge whether the deformation of the surrounding rock can ensure the normal use of the roadway and whether the support method can meet the requirements of safe production of the roadway. Therefore, the observation method of multisection rapid roadway surface convergence is essential to measure the safety of the roadway. The principle is to set up dense measuring stations at a certain distance in the excavated roadway with a 
TABLE 2: Lithology and physical and mechanical parameters of the roof of the entry.

\begin{tabular}{|c|c|c|c|c|c|c|}
\hline Terrane & Lithology & $\begin{array}{l}\text { Body force } \gamma_{i} \\
\left(\mathrm{kN} / \mathrm{m}^{3}\right)\end{array}$ & $\begin{array}{l}\text { Seam thickness } h_{i} \\
(\mathrm{~m})\end{array}$ & $\begin{array}{c}\text { Elasticity modulus } E_{i} \\
(\mathrm{GPa})\end{array}$ & $\begin{array}{l}\text { Strength of extension } R_{t i} \\
(\mathrm{MPa})\end{array}$ & $\begin{array}{c}\text { Compressive strength } R c_{i} \\
(\mathrm{MPa})\end{array}$ \\
\hline 1 & Mudstone & 26 & 1.6 & 15 & 2.5 & 65 \\
\hline 2 & $\begin{array}{c}\text { Fine } \\
\text { sandstone }\end{array}$ & 25.6 & 2.25 & 35 & 6.6 & 106 \\
\hline 3 & Mudstone & 26 & 2.76 & 15 & 2 & 95 \\
\hline 4 & $\begin{array}{c}\text { Fine } \\
\text { sandstone }\end{array}$ & 27 & 1.04 & 35 & 8 & 82 \\
\hline 5 & Mudstone & 25 & 5.81 & 16 & 7 & 75 \\
\hline
\end{tabular}

\begin{tabular}{|c|c|c|c|c|c|c|c|c|}
\hline $\begin{array}{l}\text { Roof } \\
\text { Strata }\end{array}$ & \multicolumn{2}{|c|}{ Lithology } & Columnar & $\begin{array}{c}\text { Seam } \\
\text { thickness } \\
(\mathrm{m})\end{array}$ & $\begin{array}{c}\text { Body force } \\
\left(\mathrm{kN} / \mathrm{m}^{3}\right)\end{array}$ & $\begin{array}{c}\text { Elastic } \\
\text { modulus } \\
(\mathrm{GPa})\end{array}$ & $\begin{array}{l}\text { Strength of } \\
\text { extension } \\
\text { (MPa) }\end{array}$ & $\begin{array}{l}\text { Compressive } \\
\text { strength } \\
(\mathrm{MPa})\end{array}$ \\
\hline 7 & \multicolumn{2}{|c|}{ Mudstone } & & 2.23 & 25.0 & 15 & 7 & 65 \\
\hline 6 & \multicolumn{2}{|c|}{ Siltstone } & & 1.05 & 27.0 & 35 & 6 & 105 \\
\hline 5 & \multicolumn{2}{|c|}{ Mudstone } & & 5.81 & 25.0 & 16 & 2.5000 & 65 \\
\hline 4 & \multicolumn{2}{|c|}{ Siltstone } & & 1.04 & 27.0 & 35 & 6.6000 & 106 \\
\hline \multirow{2}{*}{3} & \multirow{2}{*}{ Mudstone } & \begin{tabular}{|c|}
$\begin{array}{c}\text { Carbonaceous } \\
\text { Mudstone }\end{array}$ \\
\end{tabular} & & 0.20 & 25.7 & 14 & 3 & 100 \\
\hline & & Mudstone & & 2.56 & 26.0 & 15 & 2 & 95 \\
\hline 2 & \multicolumn{2}{|c|}{ Fine sandstone } & & 2.25 & 25.6 & 35 & 8 & 82 \\
\hline 1 & \multicolumn{2}{|c|}{ Mudstone } & 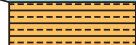 & 1.60 & 26.0 & 15 & 7 & 75 \\
\hline 0 & \multicolumn{2}{|c|}{ 2\# coal seam } & & 1.62 & l & l & l & I \\
\hline
\end{tabular}

FIGURE 8: The geological comprehensive histogram of 2\# coal seam.

TABLE 3: Calculation of the values of each parameter of $x_{0}$.

\begin{tabular}{lcccccccc}
\hline Parameter & $\gamma\left(\mathrm{kN} / \mathrm{m}^{3}\right)$ & $H(\mathrm{~m})$ & $m(\mathrm{~m})$ & $k$ & $A$ & $P_{x}(\mathrm{KPa})$ & $C_{0}(\mathrm{KPa})$ & $\varphi\left(^{\circ}\right)$ \\
\hline Value & 25 & 230 & 1.8 & 2 & 0.5 & 125 & 40 & 30 \\
\hline
\end{tabular}

TABLE 4: Calculation of the values of each parameter of the hanging arch length.

\begin{tabular}{lccccccccc}
\hline Parameter & $x_{0}(\mathrm{~m})$ & $H(\mathrm{~m})$ & $l_{0}(\mathrm{~m})$ & $q(\mathrm{KPa})$ & $q_{0}(\mathrm{KPa})$ & $P(\mathrm{KPa})$ & $R_{t}(\mathrm{MPa})$ & $n$ & $h$ \\
\hline Value & 2.98 & 230 & 4.2 & 124.9 & 100 & 416.7 & $2 \sim 2.5$ & 3 & 1.9 \\
\hline
\end{tabular}

considerable length. Each observation station conducts highfrequency observations from its initial setup. The space is exchanged for time, and the law of surrounding rock deformation is mastered in a relatively short period.

(1) Survey Station Arrangement. The station layout is based on the cross-point method (see Figure 10).

The rules of station layout are as follows. Taking the direction of advancement of 2103 working face as the positive direction, point $\mathrm{A}$ is located on the nonrecovery side of the entry; point $B$ is located on the recovery side; point $C$ is located on the roof of the entry; point $\mathrm{D}$ is located on the floor of the entry. When the measurement points are laid out, short anchor rods and reflective stickers are posted at points $\mathrm{A}, \mathrm{B}, \mathrm{C}$, and $\mathrm{D}$ as permanent observation points.
(2) Spacing of Measuring Stations. The layout of the measuring station should take into account the speed of the working face and the law of mine pressure appearing in the entry. When the retrieval speed of the working face is faster, the measurement station should be arranged denser to increase the sampling frequency of deformation of the entrysurrounding rocks in time and space. According to the advance rate of the working face, the spacing of the measuring station arrangement is $10 \mathrm{~m}$. The track crossheading of the 2103 working face is arranged in the whole range (see Figure 11).

According to the original data of each measurement point and the monitoring results, Figure 11 shows the analysis. The horizontal coordinate of the graph indicates the 


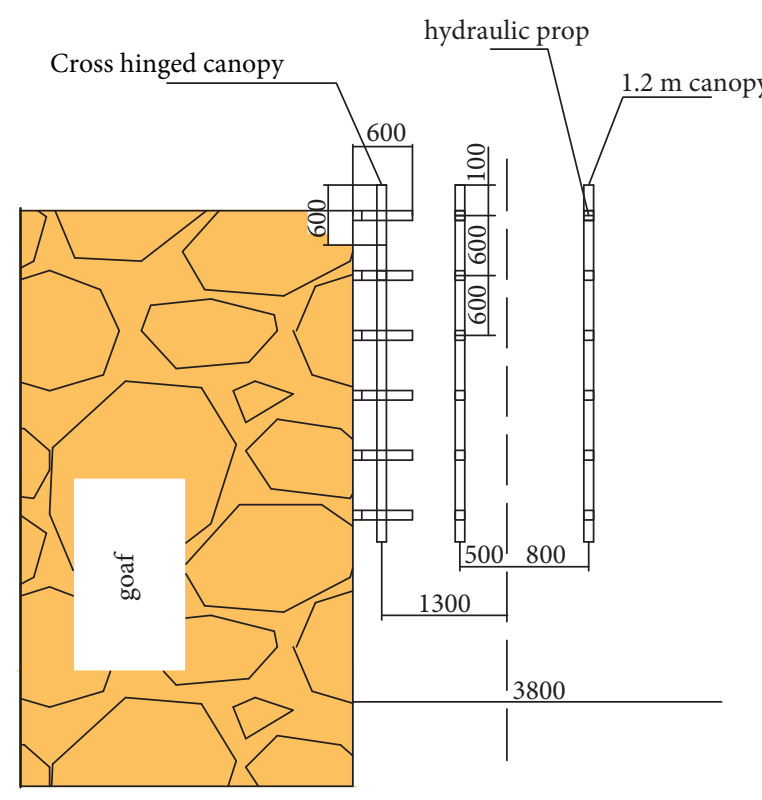

(a)

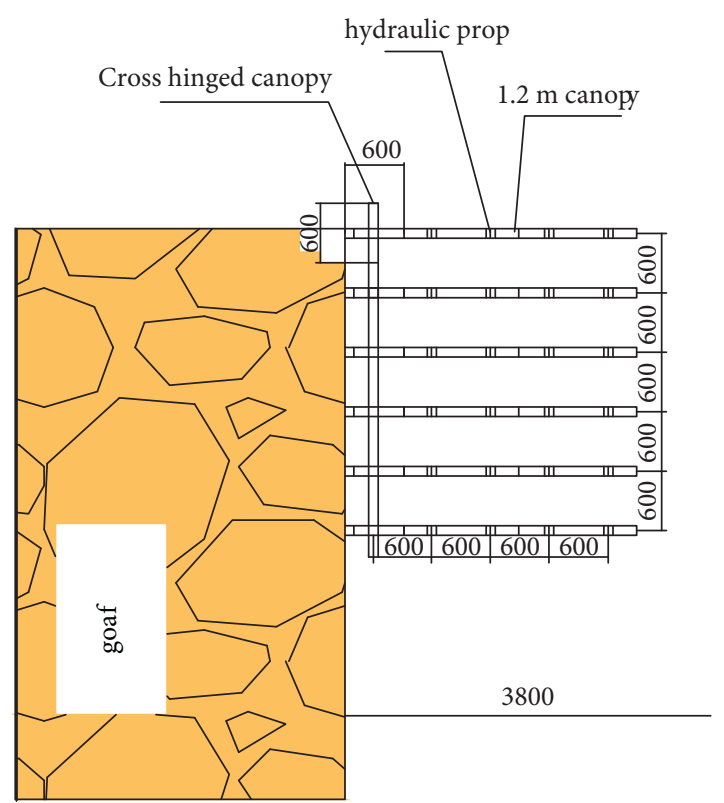

(b)

FIGURE 9: Support method of the crossheading along the gob-side entry retaining. (a) Normal section. (b) Crushed roof section.

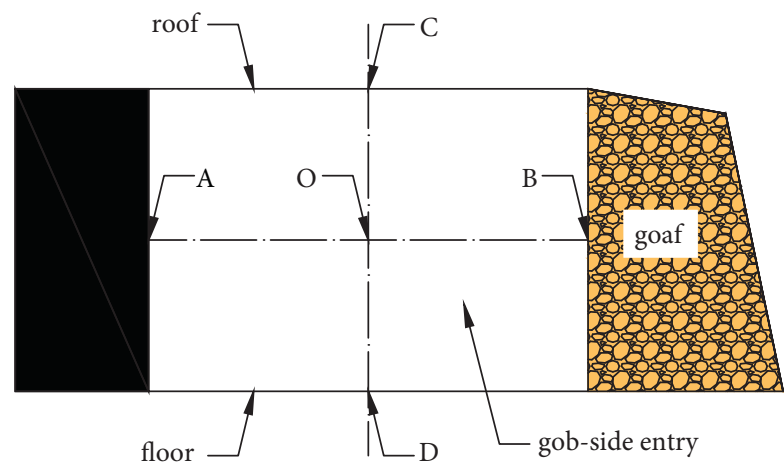

FIGURE 10: Measuring-point arrangement of surface displacement.

distance of the monitoring point from the current working face, with the direction of the working face advancement as the positive direction and the direction of the mining void area as the negative direction. The vertical coordinates indicate the displacement of each monitoring point.

It should be noted that in Figure 12, the range from 0 to $-300 \mathrm{~m}$ has been mined, and the range from 0 to $300 \mathrm{~m}$ is the range that has not been mined. So, it is the deformation of goaf from 0 to $-300 \mathrm{~m}$ about "distance of goaf" in Figure 12. On the other hand, it is the deformation of coal wall from 0 to $300 \mathrm{~m}$ about "distance of goaf" in Figure 12. The range from 0 to -300 on one side of the goaf in Figure 12 shows the deformation on one side of the goaf within the mined range.

\subsubsection{Analysis of Observation Results}

(1) Entry-retaining section is as follows: the average width of the entry in the entry-retaining section of 2103 working face was $3,620 \mathrm{~mm}$, and the deformation of the two gangs was mainly for the solid coal gangs. The average height of the entry was $1,991 \mathrm{~mm}$, and the roof and bottom plates were between 300 and $800 \mathrm{~mm}$. Besides, the compression deformation of the coal mass and rock mass on the solid coal side was also large, generally around $300 \mathrm{~mm}$.

(2) Advanced-supporting section is as follows: the advanced-supporting distance was $60 \mathrm{~m}$, and the average width and height of the entry in this section were 3,928 and $2,104 \mathrm{~mm}$, respectively. The two gangs were shifted $100-150 \mathrm{~mm}$, with the heaving floor above $200 \mathrm{~mm}$ and the roof sinking less than $50 \mathrm{~mm}$.

(3) The average width and height of the entry from the advanced-supported section to the $250 \mathrm{~m}$ entry in front of the working face were 4,043 and $2,110 \mathrm{~mm}$, respectively. The convergence and deformation of the entry were not obvious, with the displacement of the two gangs less than $100 \mathrm{~mm}$ and the sinking of the roof less than $50 \mathrm{~mm}$. There was no obvious separation between the anchor rod anchorage area and the anchor cable anchorage area.

In summary, the overall entry in the track crossheading of the 2103 working face is good (see Figure 13), but the monitoring of mine pressure should be further strengthened, especially the change of top plate sinking and monolithic support force. In addition to the collapse column and other structural areas that need to be observed, it does not need to reinforce the entry and the pre-mining roof. After retaining the entry according to the law of mine pressure monitoring, the retraction was performed gradually and orderly. 


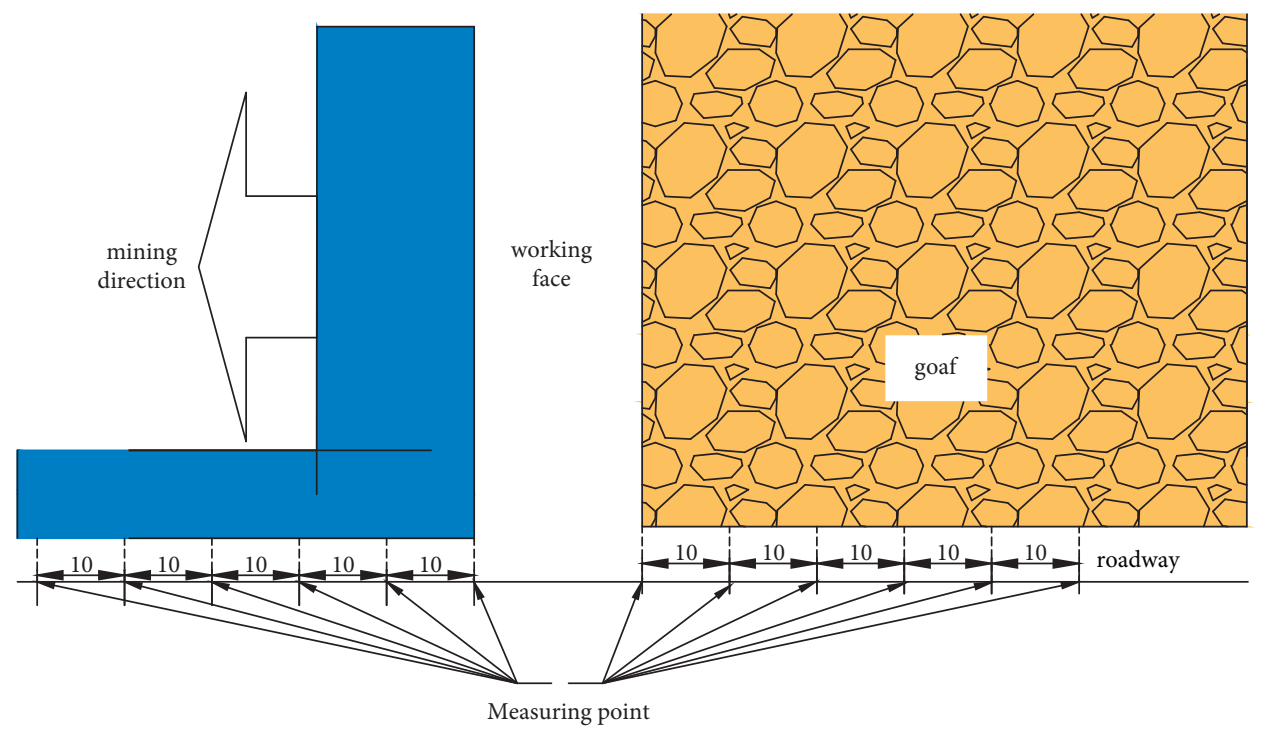

FIgURE 11: Station layout.

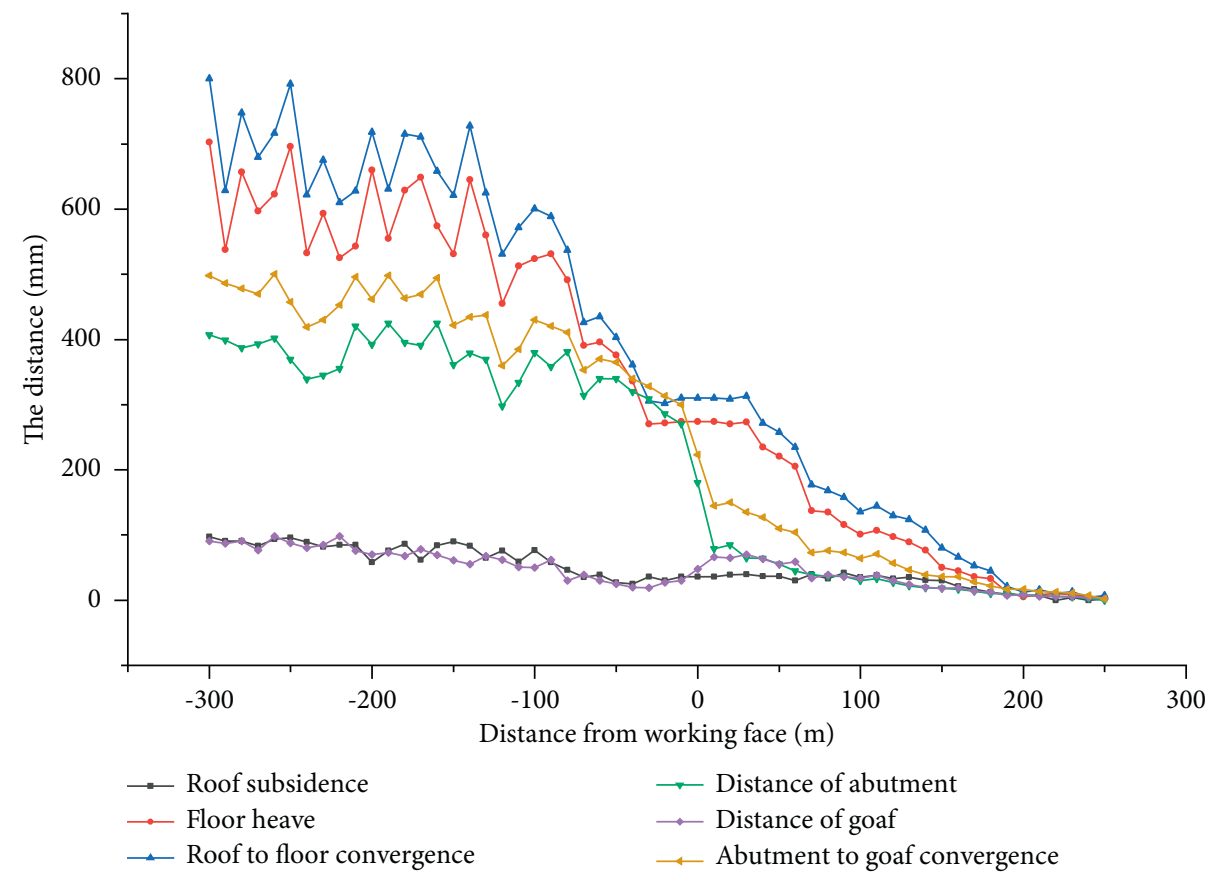

FIGURE 12: Deformation of the track crossheading of the 2013 working face.

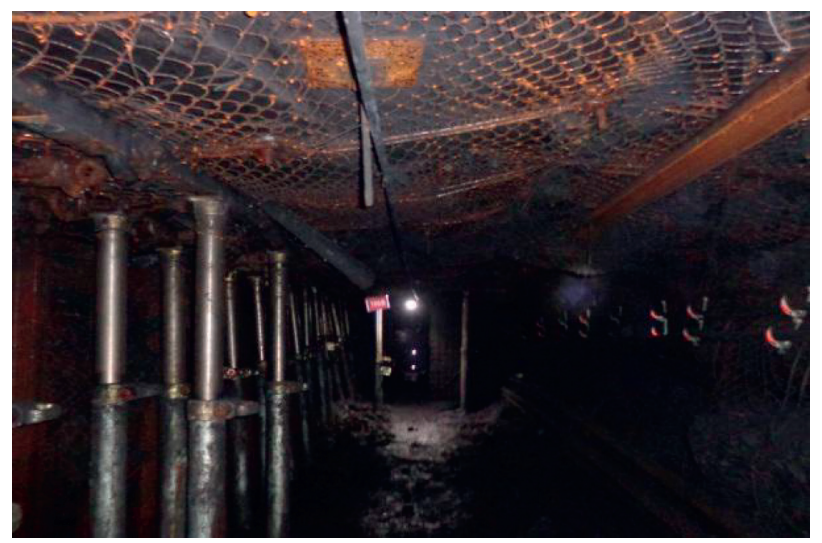

FIGURE 13: Effect of retaining the entry in the track crossheading of the 2103 working face. 


\section{Conclusions}

In this paper, we studied the ultimate hanging arch length of the layered roof with anchors and the gob-side entry retaining by theoretical analysis, numerical simulation, and field test. The following results were obtained:

(1) A simplified mechanical model of the cantilever beam in the stable period of the layered roof with anchors was established, and the theoretical formula of its ultimate hanging arch length was derived accordingly. The local sensitivity analysis method was used to study the priority of the influencing factors of the ultimate hanging arch length. The width of the plastic zone had the greatest influence on the hanging arch length, followed by the width of the roadway, support strength, anchorage strength, layered thickness, mining depth, and the ultimate tensile strength orderly. Based on this formula, the ultimate hanging arch length of the roof of the intake airway at the 2103 working face of coal 2\# in a mine in Shanxi was $10.2-10.5 \mathrm{~m}$, which was consistent with the actual observation on site.

(2) The mechanical model of the interaction between the entry-side support and the immediate roof was constructed when the immediate roof collapsed, and the calculated expression of the initial support resistance of the immediate roof was analyzed. Initial support resistance $P_{u}=(166.7-229.2) \mathrm{kN} / \mathrm{m}$ was obtained from this formula for the intake airway of the 2103 working face of coal 2\# in a mine in Shanxi, according to which the initial uniaxial compressive strength of the roadside support body should be not less than $0.46 \mathrm{MPa}$.

(3) According to the theoretical calculation of the ultimate hanging arch length and the initial support resistance value of the entry-side support, guidance was given to the process of retaining the entry along the intake airway of the 2103 working face. The observation showed that the sinkage of the roof of the entry-retaining section was controlled below $100 \mathrm{~mm}$, and that of the advanced section was controlled below $50 \mathrm{~mm}$. The overall effect of the entry was good and met the requirements, which provides a strong guarantee for the stability control of roadway surrounding rock and mine safety production.

\section{Data Availability}

The data used in the field measurement can be obtained from the first author upon request.

\section{Conflicts of Interest}

The authors declare no potential conflicts of interest with respect to the research, authorship, and/or publication of this article.

\section{Acknowledgments}

The authors acknowledge the financial support for this work provided by the 2021 Year Postgraduate Research and Practice Innovation Project of Jiangsu Province (Grant no. KYCX21_2382) and the National Natural Science Foundation of China (Grant no. 51204159).

\section{References}

[1] X. Z. Hua and P. Yang, "Floor deformation dynamic evolution of gob-side entry retaining with large section in deep mine," Journal of China University of Mining and Technology, vol. 47, no. 3, pp. 494-501, 2018.

[2] N. Zhang, H. Chen, and Y. Chen, "An engineering case of gobside entry retaining in one kilometer-depth soft rock roadway with high ground pressure," Journal of China Coal Society, vol. 40, no. 3, pp. 494-501, 2015.

[3] P. Yang, X. Z. Hua, Y. F. Li, Q.-J. Liu, and S. Yang, "Backfill horizontal stability analysis of gob-side entry retaining with compound roof in deep mine," Rock and Soil Mechanics, vol. 40, no. 3, pp. 405-411, 2018.

[4] X. Wang and F.-B Meng, "Statistical analysis of large accidents in China's coal mines in 2016," Natural Hazards, vol. 92, no. 1, pp. 311-325, 2018.

[5] Y. Chen, J. B. Bai, T. L. Zhu, S. Yan, S.-H. Zhao, and X. C. Li, "Mechanisms of roadside support in gob-side entry retaining and its application," Rock and Soil Mechanics, vol. 35, no. 5, pp. 1427-1432, 2012.

[6] P. Yang, X. Z. Hua, Q. J. Liu, M. Yang, and S. X. Cheng, "Experimental study of dynamic evolution characteristic of floor fractal dimension of gob-side entry retaining with large section in deep mine," Rock and Soil Mechanics, vol. 38, no. S1, pp. 351-358, 2017.

[7] H. P. Kang, D. L. Niu, Z. Zhang, L. Jian, Z. H. Li, and F. J. Fan, "Deformation characteristics of surrounding rock and supporting technology of gob-side entry retaining in deep coal mine," Chinese Journal of Rock Mechanics and Engineering, vol. 29, no. 10, pp. 1977-1987, 2010.

[8] Q. Q. Zheng, Y. Xu, H. Hu, J.-W. Qian, Q. Zong, and P. Xie, "Fracture and tomography of velocity structures of sandstone under uniaxial loads," Chinese Journal of Geotechnical Engineering, vol. 43, no. 6, pp. 1069-1077, 2021.

[9] Y. F. Li and X. Z. Hua, "Mechanical analysis of stability of key blocks of overlying strata for gob-side entry retaining and calculating width of roadside backfill," Rock and Soil Mechanics, vol. 29, no. 10, pp. 1134-1140, 2012.

[10] H. M. Li, "Control design of roof rocks for gob-side entry," Chinese Journal of Rock Mechanics and Engineering, vol. 29, no. 10, pp. 651-654, 2000.

[11] W. B. Xie, "Influence factors on stability of surrounding rocks of gob-side entry retaining in top-coal caving mining face," Chinese Journal of Rock Mechanics and Engineering, vol. 29, no. 10, pp. 3059-3065, 2004.

[12] C. L. Han, N. Zhang, J. G. Kan, and Z. Ran, "Mechanism and application of double active control with pressure-relieving and an choring for gob-side entry retaining," Journal of China Coal Society, vol. 42, no. S2, pp. 323-330, 2017.

[13] Z. Z. Zhang, J. B. Bai, W. J. Wang, Y. Chen, and X. Y. Yu, "Stuly on stress state of immedialte roof above backill area in gob-side entry retainingand its application," Journal of China Coal Society, vol. 48, no. 8, pp. 1960-1970, 2017.

[14] X. G. Zheng, T. L. An, Y. Guo, C. Liu, and X. Cheng, "Surrounding rock control mechanism and engineering 
application of in-situ coal pillar in gob-side entry retaining," Journal of Mining \& Safety Engineering, vol. 35, no. 6, pp. 1091-1098, 2018.

[15] J. G. Kan, J. K. Wu, N. Zhang, and D. X. Liang, "Structure stability analysis and control technology of surrounding rock of the secondary gob-side entry retaining," Journal of Mining \& Safety Engineering, vol. 35, no. 5, pp. 877-884, 2018.

[16] J. K. Wu, J. G. Kan, F. X. Xie, and Z. Yang, "Study on deformation and failure characteristics of deep gob-side entry retaining roof and the controlling countermeasures," Journal of Mining \& Safety Engineering, vol. 34, no. 1, pp. 16-23, 2017.

[17] L. Gu, Z. Wang, Q. Huang, G. Ye, and F. Zhang, "Numerical investigation into ground treatment to mitigate the permanent train-induced deformation of pile-raft-soft soil system," Transportation Geotechnics, vol. 24, pp. 100368-8, 2020.

[18] Z. Wang, L. Gu, Q. Zhang, and B.-A. Jang, "Influence of initial stress and deformation states on the shear creep behavior of rock discontinuities with different joint roughness coefficients," Rock Mechanics and Rock Engineering, pp. 1-14, 2021.

[19] S. Ji, H. He, and J. Karlovšek, "Application of superposition method to study the mechanical behaviour of overlying strata in longwall mining," International Journal of Rock Mechanics and Mining Sciences, vol. 146, pp. 1-15, 2021.

[20] W. B. Guo, C. Y. Liu, F. F. Wu, S. F. Wu, and P.-J. Yang, "Analyses of support crushing accidents and support working resistance in large mining height workface with hard roof," Journal of China Coal Society, vol. 39, no. 7, pp. 1212-1219, 2014.

[21] Q. X. Huang, M. Y. Zhao, and K. J. Huang, "Study of roof double key strata structure and support resistance of shallow coal seams group mining," Journal of China University of Mining \& Technology, vol. 48, no. 1, pp. 71-77+86, 2019.

[22] J. L. Gao, H. H. Cai, and F. C. Lu, "Study on underlying coal seam stress distributiong and failure charecterics in slicing mining of extra-thick coal seams," Coal Science and Technology, vol. 49, no. 5, pp. 19-26, 2021.

[23] X. Hua, G. Chang, X. Liu et al., "Three-dimensional physical simulation and control technology of roof movement characteristics in non-pillar gob-side entry retaining by roof cutting," Shock and Vibration, vol. 2021, Article ID 7491414, 13 pages, 2021.

[24] Z. W. Wu and H. Z. Song, "Determination of impact factors on temperature field in dam based on global sensitivity analysis method," Journal of Hydraulic Engineering, vol. 29, no. 10, pp. 737-742, 2011.

[25] Q. S. He, Y. M. Yang, and S. F. Xiao, "Neural network method in parametric probabilistic sensitivity analysis and its application," Chinese Journal of Computational Mechanics, vol. 28, no. 4, pp. 29-32, 2011.

[26] J. Song and Z. Z. Lu, "Moment method based on fuzzy reliability sensitivity analysis for a degradable structural system," Chinese Journal of Aeronautics, vol. 21, pp. 518-525, 2008.

[27] C. H. Zhao, "Analysis on local and overall sensitivity of high pressurized hydrological parameters of aquifer," Coal Science and Technology, vol. 41, no. 8, pp. 110-113, 2013.

[28] Z. J. You, H. L. Fu, C. A. You et al., "Stress transfer mechanism of soil anchor body," Rock and Soil Mechanics, vol. 39, no. 1, pp. 85-92+102, 2018.

[29] X. Z. Hua, S. H. Zhao, H. Zhu, and H. Hu, "Research on combined support technique of gob-side entry retaining," Rock and Soil Mechanics, vol. 27, no. 12, pp. 2225-2228, 2006. 